Ю. О. Данілов ${ }^{1}$, В. В. Стадник ${ }^{2}$

${ }^{1}$ Центральне управління технічного забезпечення Повітряних Сил Збройних Сил України, Київ

${ }^{2}$ Харківський національний університет Повітряних Сил імені Івана Кожедуба, Харків

\title{
МОДЕЛЮВАННЯ ПРОЦЕСУ ФУНКЦІОНУВАННЯ ШТУЧНОГО ЗСУВУ ПОВІТРЯНИХ МАС В АТМОСФЕРІ
}

\begin{abstract}
Штучний зсув повітряних мас (ШЗПМ), спричинений вивільненням великої кількості енергії в повітряному просторі, $є$ аналогом природного зсуву вітру, але може бути набагато потужнішим. Штучний зсув повітряних мас розглядається як зсув вітру синусоїдального типу, описаного відповідною системою диференційних рівнянь зміни газодинамічних характеристик навколишнього середовища при потужних вибухах. Він може мати значний вплив на стійкість та керованість, зміну маневрових можливостей і траєкторії літального апарату. Мета статті - провести аналіз проведених досліджень формування ШЗПМ та моделювання цього явища в атмосфері з отриманням результатів зміни основних характеристик. Запропонована математична модель цього явища для дослідження впливу його на динаміку руху літального апарату дозволила провести чисельний експеримент. Це в подальшому дасть змогу відпрацювати рекомендації по зменшенню впливу штучного зсуву повітряних мас та запобіганню попадання в зони його рушійної дії. Можливе застосування цього явища для зменшення ефективності дій авіації противника.

Ключ ов і слов а: штучний зсув повітряних мас, ударна хвиля, динаміка руху, літальний апарат, диференціальне рівняння.
\end{abstract}

\section{Вступ}

Постановка проблеми. На нинішньому етапі розвитку технологій потужні вибухи у повітрі найбільш доступні за рахунок ядерної енергії, їх можна також здійснювати з допомогою звичайної вибухової речовини, але для цього необхідна маса, еквівалентна тисячам тон, і що технічно досягти не завжди можливо та і недоцільно. У військових цілях у протиракетній та протиповітряній обороні ядерну зброю планується використовувати проти важливих повітряних і космічних цілей. Стосовно повітряних цілей, то розглядається сім факторів їх поразки. Усі вони мають тільки їм властиву фізичну природу вражаючої дії, зв'язану 3 руйнуванням об'єкту і його елементів.

До факторів поразки повітряних цілей можна віднести і зсув повітряних мас, що проявляється при потужних вибухах. Фізична природа його вражаючої дії суттєво відрізняється від дії на літальні апарати (ЛА) уже відомих факторів, тому даний зсув можна рахувати як окремий фактор, аспекти якого вимагають детального розгляду і досліджень.

Звідси виникають питання: чи можливо цей феномен застосувати як зброю, що уражає повітряну ціль на аеродинамічних принципах? Чи можливо формувати такі зсуви повітряних мас зарядами меншої потужності, але направленої дії?

Аналіз останніх досліджень і публікацій. Аналіз останніх досліджень та публікацій 3 даної тематики свідчить, що ШЗПМ може мати значний вплив на стійкість та керованість та зміну маневрових можливостей і траєкторії літального апарату. На сучасному етапі досліджень в даному напрямку було виділено ШЗПМ з ударної хвилі (УХ) і обгрунтоване це явище $[1,2]$. Також проводилися дослідження складної картини нестаціонарного обтікання профілю крила 3 дифракцією ударної хвилі, з утворенням відривів потоку та інтенсивних вихорів, що ускладнюють розрахунки і аналіз сил і моментів, які діють на тіло. Як показано в роботах [3-5], ці неста- ціонарні сили можуть суттєво відрізнятися від сил, розрахованих по квазістаціонарній теорії, та враховано степінь нестаціонарності обтікання крила для конкретного типу ЛА з розрахунком часу його знаходження в ШЗПМ [2].

Мета статті - провести аналіз проведених досліджень формування ШЗПМ та моделювання цього явища в атмосфері з отриманням результатів зміни основних характеристик.

\section{Виклад основного матеріалу}

ШЗПМ - це відносна зміна швидкості руху повітряних мас за величиною та напрямком у визначеному об'ємі чи прошарку атмосфери викликана внесенням великої кількості енергії в атмосферу [1]. ШЗПМ формується як складова ударної хвилі. Швидкість руху ШЗПМ $U$ залежить від потужності q та висоти вибуху $H$ в умовах безмежної атмосфери.

У самому спрощеному вигляді модель ШЗПМ нагадуватиме модель зсуву вітру. Його природа добре вивчена у світовій практиці, реалізована на моделях і не вимагає додаткових доказів щодо наслідків [6-10]. Процедура розрахунку параметрів УХ і ШЗПМ за нею при потужних вибухах являє собою лінеаризовану систему диференційних рівнянь. Вона описує параметри руху ударної хвилі і ШЗПМ і відповідні їх параметри у точці зустрічі з ЛА та при їх сумісному русі.

Підсистема математичної моделі ШЗПМ тісно пов'язана 3 підсистемою навколишнє середовище, адже параметри ШЗПМ залежать від стану атмосфери та її основних характеристик $[11,12]$.

Отже, ми маємо модель ШЗПМ (1-9), яку приводимо у кінцевому вигляді для плоскої УХ (сферичністю ударної хвилі на великих відстанях відносно малих розмірів ЛА можна знехтувати) $[1,5,11-23]$ :

$$
\begin{gathered}
\tau_{+}=1,3 \cdot 10^{-3} \cdot \sqrt{R} \cdot \sqrt[3]{q} ; \\
\tau_{-}=0,1 \cdot \sqrt[3]{q} ;
\end{gathered}
$$




$$
\begin{aligned}
& \rho_{\phi}=\rho_{H} \cdot \frac{(k+1) \cdot \Delta \mathrm{P}_{\phi}+2 \cdot k \cdot \mathrm{P}_{H}}{(k-1) \cdot \Delta \mathrm{P}_{\phi}+2 \cdot k \cdot P_{H}} ; \\
& T_{\phi}=T_{0} \cdot \frac{P_{\phi} \cdot \rho_{0}}{\rho_{\phi} \cdot P_{0}} ; \\
& \Delta \mathrm{P}_{\phi}=8.8 \cdot \frac{\sqrt[3]{q}}{r}+240 \cdot \frac{\sqrt[3]{q^{2}}}{r^{2}}+6000 \cdot \frac{q}{r^{3}} ; \\
& \Delta \mathrm{P}=f\left(\Delta \mathrm{P}_{\phi}, t_{\phi} \cdot \frac{D_{\phi}}{D_{\phi}-V_{x g} \cdot \cos \Theta_{w}}\right) ; \\
& D_{\phi}=\sqrt{\frac{\Delta \mathrm{P} \cdot \rho_{\phi}}{\left(\rho_{\phi}-\rho_{H}\right) \cdot \rho_{H}}} ;
\end{aligned}
$$

$$
\begin{gathered}
U=\sqrt{\Delta \mathrm{P} \cdot\left(\rho_{\phi}-\rho_{H}\right) /\left(\rho_{H} \cdot \rho_{\phi}\right)} ; \\
\frac{P_{\phi}}{P_{H}}=\frac{(k+1) \cdot \rho_{\phi}-(k-1) \cdot \rho_{H}}{(k+1) \cdot \rho_{H}-(k-1) \cdot \rho_{\phi}} .
\end{gathered}
$$

Використовуючи рівняння (1-9) математичної моделі штучного зсуву повітряних мас та рівняння муємо графічну залежність параметрів штучного зсуву повітряних мас від висоти розповсюдження ударної хвилі $H$, потужності вибуху та відстані від епіцентру вибуху $R$ (рис. 2,3 ).

Із отриманих графічних залежностей полягає:

- зі збільшенням висоти при одній і тій самій (7) відстані від центра вибуху швидкість руху повітряних мас за УХ зростає;

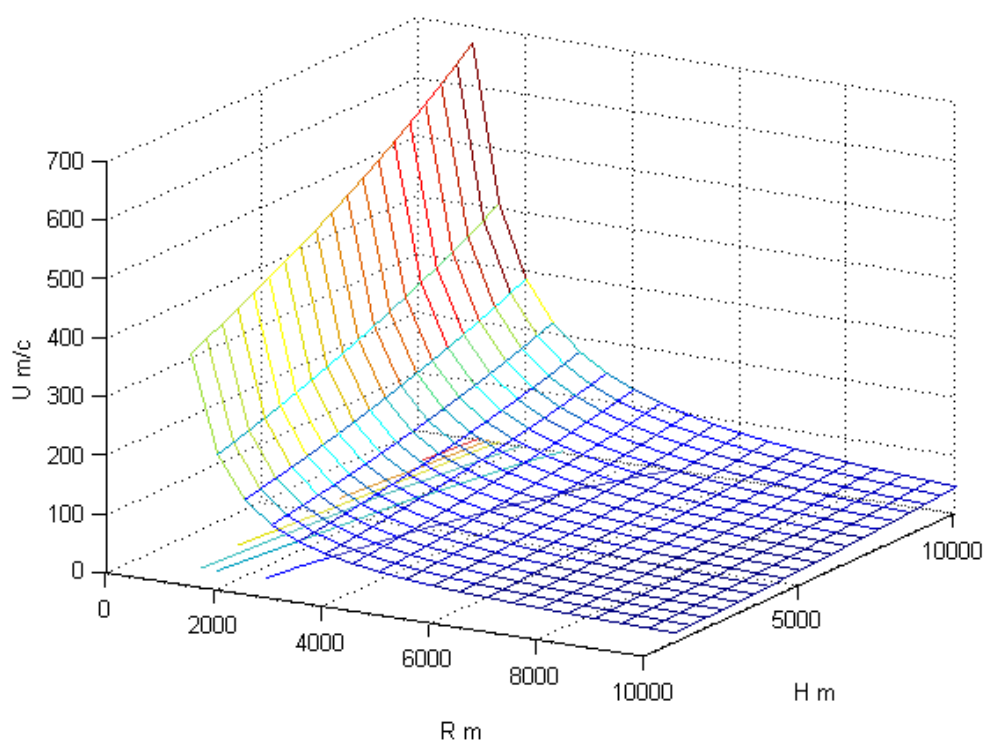

Рис. 2. Залежність зміни швидкості повітряних мас за УХ від відстані до центру вибуху та висоти розповсюдження УХ

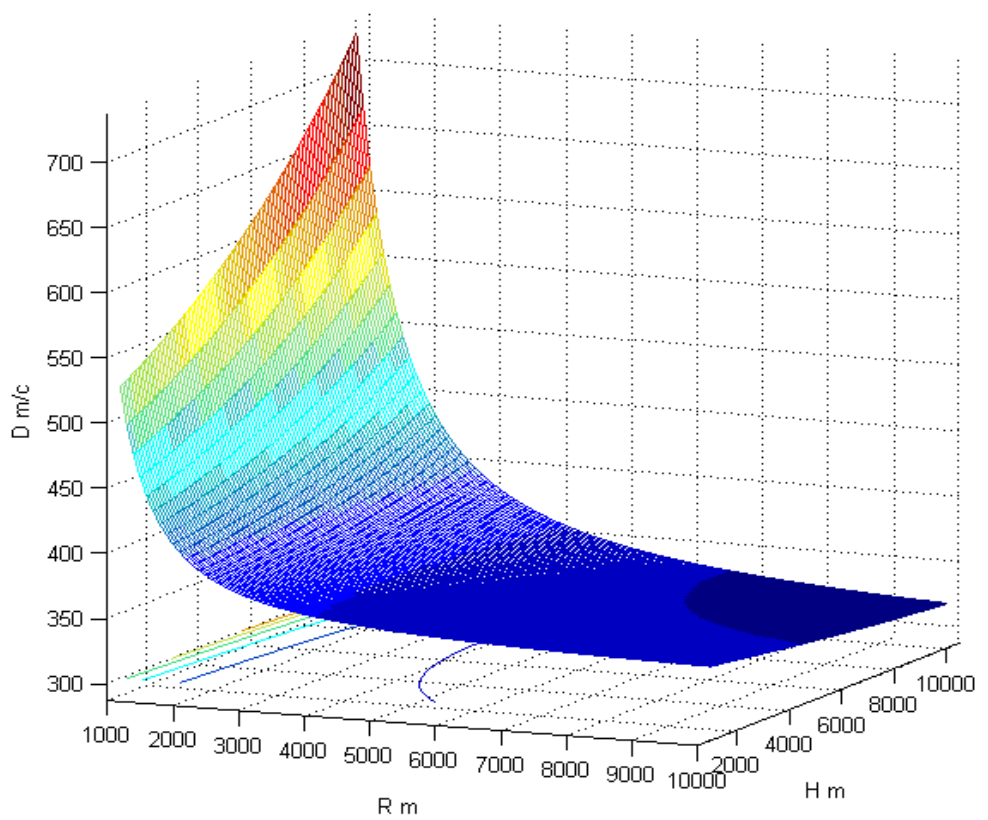

Рис. 3. Залежність швидкості проходження фронту УХ від висоти $H$ та відстані від центру вибуху $R$ 
- швидкість розповсюдження ударної хвилі на різних відстанях від центру вибуху змінюється по різному. На близькому віддаленні від центру вибу$\mathrm{xy}$, де $\mathrm{YX}$ ще має велику кінетичну та потенційну енергії, швидкість розповсюдження з висотою збільшується, але на великих відстанях вона зменшується значно більше;

- градієнти зміни швидкості руху повітряних мас по висоті мають різний характер в залежності від потужності ударної хвилі. Тобто при $\mathrm{R}=1000 \mathrm{м}$, $\Delta \mathrm{P}=2,53 \mathrm{\kappa гc} / \mathrm{M}^{2}$ швидкість ШЗПМ 3 висотою буде змінюватись від 350 до $600 \mathrm{~m} / \mathrm{c}$, а при $\mathrm{R}=3000$ м від 58 до $90 \mathrm{M} / \mathrm{c}$;

- час дії фази стискання також зі збільшенням висоти збільшується.

Вивчення формування i поширення ударних хвиль у реальному газі дає багатий матеріал для побудови теорії хвильових процесів у хімічно реагуючому середовищі [5]. Розгляд таких процесів методом розривів дозволяє дати єдиний опис фронтовим явищам різного характеру.

При повітряному потужному вибуху тиск у фронті УХ в приземному шарі повітря і їі вражаюча дія залежать не тільки від потужності, висоти вибуху і відстані від епіцентру, але й від стану поверхні землі в районі вибуху [1].

Процес дії УХ на ЛА значно складніший від дії зсуву вітру і вже не може розглядатись як квазістаціонарний. Це викликано тим, що він зв'язаний не лише зі швидкостями руху, але і з тиском та щільністю повітряних мас. Крім того, газодинамічні зміни на фронті УХ та наступному за нею ШЗПМ, на відміну від зсуву вітру, більш швидкоплинні, особливо у порівнянні з власними динамічними властивостями літальних апаратів. Крім всебічного обтискання i тиску відбиття ударної хвилі, починається зміна аеродинамічних сил та моментів ЛА. Це обумовлюється потоком ШЗПМ за фронтом ударної хвилі, швидкість якого векторно складається зі швидкістю обтікаючого на ЛА потоку, яку він мав до дії ударної хвилі.

Сумарна швидкість потоку відрізняється від початкової як за величиною, так і за напрямком. Як наслідок, при цьому різко міняється швидкісний напір, кути атаки, ковзання, тангажу, крену і рискання літального апарату.

Значна зміна кутів атаки і ковзання приводить до необхідності забезпечити безпеку польоту за стійкістю і керованістю ЛА. Це пояснюється тим, що у процесі непостійності руху при дії ШЗПМ ЛА може вийти на закритичні режими 3 наступним звалюванням та входом у штопор і т. п. В іншому випадку можуть бути перевищені обмеження за перевантаженням, установлені для конкретного типу ЛА. Штучний зсув повітряних мас може мати значний вплив на стійкість та керованість та зміну маневрових можливостей і траєкторії літального апарату.

\section{Висновки}

Отже штучний зсув повітряних мас (аналог зсуву вітру) є небезпечне явище, яке необхідно досконально досліджувати, але проведення досліджень в натуральних умовах неможливе із-за великих витрат. Запропонована математична модель цього явища для дослідження впливу його на динаміку руху літального апарату дозволила провести чисельний експеримент. Це в подальшому дасть змогу відпрацювати рекомендації по зменшенню впливу штучного зсуву повітряних мас та запобіганню попадання в зони його рушійної дії.

Також можливе застосування цього явища для зменшення ефективності дій авіації противника.

\section{СПИСОК ЛІТЕРАТУРИ}

1. Корочкін О.А. Ураження аеродинамічних літальних апаратів за рахунок зсуву повітряних мас при потужних вибухах / Корочкін О.А., Литвинчук М.І., Костаков А.Г.// Збірник наукових праць Харківського військового університету. Випуск №3(41) -2002. - с.151-153.

2. Колодяжний О.І. Моделювання небезпечних зон впливу штучного зсуву повітряних мас на динаміку руху високоманевреного літака. / О.І. Колодяжний, О.І. Тимочко. // Системи обробки інформації, - 2017. Вип. 1(147). - С. 80-87.

3. Иванов А. Н. Исследование обтекания конических тел нестационарным потоком газа за сферической ударной волной. / А. Н. Иванов // - Труды ЦАГИ, 1983. - Вып. 2184 - С. 3-26.

4. Иванов А. Н. О действии нестационарного потока газа на плоскую пластину. / А. Н. Иванов // Труды ЦАГИ, 1983. Вып 2184 - С. $27-33$

5. Ляхов В.Н. Воздействие ударных волн и струй на элементы конструкций. / В.Н. Ляхов // М.: Машиностроение. 1989. $-392 \mathrm{c}$.

6. Ранцан Я.Я. Динамическая реакция самолёта при воздействии двумерного поля скорости вертикального порыва ветра./ Я. Я. Ранцан // Научно-методические материалы по аэроупругости летательных аппаратов. - 1983. Вып. 1302. - C. $108-115$

7. Трунов О. К. Влияние сдвига ветра на взлет и посадку самолетов. / О. К. Трунов, Л. И. Журавлев. - М.: ГосНИИ ГА, 1979. - $148 \mathrm{c.}$

8. Обрубов А. Г. Динамика самолёта в условиях сдвига ветра. / А. Г. Обрубов, В. Е. Грязин // Труды ЦАГИ. - 1983. Вып. 2163. - C. 3-24.

9. K. R. Goff. Wind and wind shear Tech Center FAR. / K. R. Goff. Wist Poc 2 ICAO Monterial, 1981. — 284 c.

10. Руководство по сдвигу ветра на малых высотах Doc9817 AN/449, ICAO, 2005. — 258 c.

11. Макеев В.И. Математическая модель динамики полёта летательных аппаратов в возмущённой среде. / В.И. Макеев, Н.Н. Ляпа, С.П. Латин, П.Е. Трофименко // - Электронное моделирование, - 2011. Т.33 №6. - С. 19-32.

12. Лойцнянский Л.Г.. Механика жидкости и газа / Л.Г. Лойцнянский // Издание 7-е, исправленное. - М.: ДРОФА, 2003. $-840 \mathrm{c}$.

13. Руководство по стандартной атмосфере ИКАО с верхней границей, поднятой до 80 километров (262 500 футов). Doc.7488/3. - Третье изд. - ICAO, 1993. - 305 с. 
14. Селиванов В. В. Взрывные технологии / В. В. Селиванов, И. Ф. Кобылкин, С. А. Новиков. - 2-е изд., перераб. и доп. - М: Издательство МГТУ им. Н. Э. Баумана, 2014. - 519 с.

15. Зельдович Я. Б. Физика ударных волн и высокотемпературных гидродинамических явлений. / Я. Б. Зельдович, Ю. П. Райзер. - М.: Наука, 1966. - 686 с.

16. Механическое действие ядерного взрыва / [Архипов В. Н., Борисов В. А., Будков А. М. и др.]. - М.: ФИЗМАТЛИТ, 2003. - 384 c. - ISBN 5-9221-0261-3.

17. Фатеев В. Н. Физическое и математическое моделирование усиления ударных волн: дис. на соискание ученой степени канд. физ.-матем. наук. Спец. 01.02.05 / Фатеев Владимир Николаевич. — Т., 2011. — 110 с.

18. Седов Л. И. Методы подобия и размерности в механике. Издание девятое, переработанное. / Л. И. Седов. - [Изд. 9 , перераб.]. - М.: Наука, 1981. - 448 с.

19. Kuchuk G., Kovalenko A., Komari I.E., Svyrydov A., Kharchenko V.. Improving big data centers energy efficiency: Traffic based model and method. Studies in Systems, Decision and Control, vol 171. Kharchenko, V., Kondratenko, Y., Kacprzyk, J. (Eds.). Springer Nature Switzerland AG, 2019. Pp. 161-183. DOI: http://doi.org/10.1007/978-3-030-00253-4 8

20. Svyrydov, A., Kuchuk, H., Tsiapa, O. (2018), "Improving efficienty of image recognition process: Approach and case study", Proceedings of 2018 IEEE 9th International Conference on Dependable Systems, Services and Technologies, DESSERT 2018, pp. 593-597, DOI: http://dx.doi.org/10.1109/DESSERT.2018.8409201

21. Barkovska O., Serdechnyi V. Control model of data stream transmitted over a network based on proxying technology // Informatics Control Measurement in Economy and Environment Protection. - 2018. - Vol. 8, No. 1. - P. 8-11.

22. Barkovska O. Yu., Kazmina D. R., Rosinskyi D. M., Slabouz V. V., Intellectualization of the smart house system (the agentoriented approach) // Збірник наукових праць ФМФ ДДПУ. - Слов'янськ, 2019. - Вип. 9. - С. 69-74.

23. Прандтль Л. Гидроаэромеханика. / Л. Прандтль. - М.: Изд-во иностранной литературы, 1951. — 576 с.

Рецензент: д-р техн. наук, проф. О. І. Тимочко Харківський національний університет Повітряних Сил імені Івана Кожедуба Received (Надійшла) 19.04.2019 Accepted for publication (Прийнята до друку) 26.06.2019

\author{
Моделирование процесса функционирования \\ искусственного сдвига воздушных масс в атмосфере
}

Ю. А. Данилов, В. В. Стадник

Искусственный сдвиг воздушных масс, вызванный высвобождением большого количества энергии в воздушном пространстве, является аналогом природного сдвига ветра, но может быть гораздо мощнее. Искусственный сдвиг воздушных масс рассматривается как сдвиг ветра синусоидального типа, описанного соответствующей системой дифференциальных уравнений изменения газодинамических характеристик окружающей среды при мощных взрывах. Он может иметь значительное влияние на устойчивость, управляемость, изменение маневровых возможностей и траектории летательного аппарата. Цель статьи - провести анализ проведенных исследований формирования искусственного сдвига воздушных масс и моделирования этого явления в атмосфере с получением результатов изменения основных характеристик. Предложенная математическая модель этого явления для исследования влияния его на динамику движения летательного аппарата позволила провести численный эксперимент. Это в дальнейшем позволит отработать рекомендации по уменьшению влияния искусственного смещения воздушных масс и предотвращению попадание в зоны его движущей действия. Также возможно применение этого явления для уменьшения эффективности действий авиации противника.

Ключевые слова: искусственный сдвиг воздушных масс, ударная волна, динамика движения, летательный аппарат, дифференциальные уравнения.

\title{
Modeling the process of functioning of artificial movement of air masses in the atmosphere Yu. Danilov, V. Stadnik
}

The artificial shear of air masses caused by the release of a large amount of energy in the airspace is an analogue of the natural shear of the wind, but can be much more powerful. An artificial shift in air masses is considered as a displacement of a sinusoidal wind described by the corresponding system of differential equations for changing the gas-dynamic characteristics of the environment during powerful explosions. The purpose of the article is to analyze the studies of the formation of an artificial shear of air masses and simulate this phenomenon in the atmosphere with the results of changes in the main characteristics. The simulation results are obtained, based on which conclusions are made: with increasing height at the same distance from the center of the explosion, the speed of movement of air masses behind the shock wave increases; the speed of propagation of a shock wave at different distances from the center of the explosion varies differently. At a short distance from the center of the explosion, where the shock wave still has a large kinetic and potential energy, the propagation velocity increases with height, but it decreases much more at large distances; gradients of changes in the speed of movement of air masses in height are of a different nature depending on the power of the shock wave. That is, at $R=1000 \mathrm{~m}, \Delta P=2.53 \mathrm{kgf} / \mathrm{m}^{2}$, the speed of artificial shear of air masses with height will vary from $350 \mathrm{~m} / \mathrm{s} \mathrm{to} 600 \mathrm{~m} / \mathrm{s}$, and at $R=3000 \mathrm{~m}$ from $58 \mathrm{~m} / \mathrm{s}$ to $90 \mathrm{~m} / \mathrm{s}$; the duration of the compression phase also increases with increasing height. The artificial shift of air masses is a dangerous phenomenon that needs to be thoroughly investigated, but conducting research in natural conditions is impossible due to the high cost. Therefore, it is necessary to develop a mathematical model of this phenomenon to study its effect on the dynamics of the aircraft and conduct a numerical experiment. That in the future will make it possible to work out recommendations for reducing the effect of artificial displacement of air masses and preventing them from falling into zones of its destructive effect.

Keywords: artificial air mass shift, shock wave, motion dynamics, aircraft, differential equations. 